\author{
Available online at https://www.rjtl.org \\ Volume: 1, Issue: 1, 23-27, 2020 \\ ISSN: $2708-3632$ \\ DOI: https://doi.org/10.46590/rjtl.2020.010104
}

\title{
Development of Therapeutic Cushion Using Chrysopogon Zizanioides (Vetiver) and Bamboo Fabric
}

\author{
B.Jeyanthy ${ }^{1}$, S.Karpagam Chinnammal ${ }^{2}$, R.Karthikselvam ${ }^{3}$ \\ ${ }^{1}$ Assistant Professor, Garment Designing \& Production, NIFT-TEA College of Knitwear Fashion, Tirupur, India. \\ ${ }^{2}$ Assistant Professor, Costume Design \& Fashion, Chikkanna Govt. Arts College, Tirupur, India. \\ ${ }^{3}$ Student, Garment Designing \& Production, NIFT-TEA College of Knitwear Fashion, Tirupur, India.
}

$\underline{\text { Paper Status }}$

Received : March. 2020

Accepted : April 2020

Published : May 2020

Corresponding Author

B.Jeyanthy

jeyanthybpillai@gmail.com

\begin{abstract}
Textile is the key component of every human life from birth to last rights. In the recent decade, textile sectors have shown tremendous growth through improved technology from raw materials to product design and manufacturing process. These extraordinary developments provide a path to find an innovative solution to the medical sector especially in the field of therapeutic textiles. This project is a small initiative to confer a solution for particular workforce such as truck drivers who are suffering from hemorrhoids disease. The main aim was to find an innovative therapeutic textile solution for this ailment based on ancient method of herbal treatment.
\end{abstract}

Keywords: Bamboo Fabric, Chrysopogon Zizanioides Cushion, Hemmorrhoids, Herbal cushion, Therapeutic Textiles

Citation: B.Jeyanthy, S.Karpagam Chinnammal , R.Karthikselvam. Development of Therapeutic Cushion Using Vetiver and Bamboo Fabric, Research Journal of Textile and Leather, 1(1), 23-27, 2020

\section{INTRODUCTION}

In the modern decade, people are more conscious about their health. They want to take preventive measures to lead ailment free life. This scenario has made them to search for herbal based therapeutic solution for all sorts of problems.

This is the stimulating factor for technicians to provide innovative products and thus meet out the requirements of the society. This project is a kind of therapeutic solution for particular working force, the truck drivers to diminish the impact of hemorrhoids health issue, without any adverse side effects.

For this research work, 10 truck drivers aged between 45-55, commuting from Tirupur to Bangalore and vice versa twice a week covering a distance of about 800 kilometers was selected. After a brief discussion with them, it was obvious that they had a common health issue called hemorrhoids. According to Medical world, one of the key risks caused by heat wave is dehydration and it leads to hemorrhoids. When a person sits in one place for a prolonged period of time it can rise his

body heat and that is a major cause for hemorrhoids. Further, the drivers where of the opinion that allopathic treatment controlled their problem, but had side effects. Hence, the main aim of this research work was to find an innovative therapeutic textile solution for this ailment based on our ancient method of herbal treatment.

For this purpose exclusive therapeutic cushion was prepared by the combination of Chrysopogon zizanioides commonly known as Vetiver, Bambusa vulgaris commonly known as bamboo and Abutilon Indicum commonly known as thuthi. Finally, these cushions were given to the selected truck drivers to evaluate the performance properties. Each driver reverted with their personal experience about the product and it is discussed under the results heading. 


\section{MATERIALS AND METHOD}

\subsection{Materials}

\subsubsection{Vetiver}

In India, vetiver (Figure 1) is a herb well known for its excellent medicinal benefits. It is mainly used in aroma therapy and also to make cosmetic products. Further, many research based on AUYSH explains that, it can be used to heal many diseases like heat strokes, headache, muscular ache and also to keep our body cool during extremely hot seasons. These unique medicinal values of this herb enticed us to choose vetiver as a filling material for the therapeutic cushion.

\subsubsection{Bamboo Fabric}

Bamboo fiber has been one of the most prestigious discoveries of the $21^{\text {st }}$ century by the textile sector. It is a regenerated cellulose fiber and an alternative to the viscose fiber. Further, it has distinctive properties such as, UV protection, inherent antibacterial activity, biodegradability and high durability. Apart from this, bamboo is naturally a cool fiber. This exclusiveness has drawn our attention to use bamboo fiber as lining and outer fabric for making the cushion. Nonwoven and single Jersey knitted structures (Figure 2a and b) were selected for lining and outer fabric respectively. The Bamboo Nonwoven material was sourced from South Indian Textile Research Association (SITRA), Coimbatore. Dyed Single jersey Knitted bamboo fabric was purchased from an organic clothing store located at Tirupur.

\subsubsection{Thuthi Powder (Abutilon Indicum)}

In India, Thuthi (Figure3) was consumed as food by our forefathers for its immense medicinal values. Indian medical treatments siddha and ayurvedha use this herb to cure diseases such as blood vomiting, Tuberculosis, hemorrhoids etc. As per siddha, thuti powder (Figure4) is commonly used for curing hemorrhoids and its impacts. The main advantage of thuthi is that it never creates any adverse effect to our health. Thuthi powder was purchased from nearby herbal shop.

\subsection{Methods}

\subsubsection{Preparation of Vetiver Pad}

The collected vetiver was cleaned and cut into small lengths of about 2 inches and it was converted to non-woven fabric using Needle punching process. Then, it was cut to a size of 14 " X 12" X 1" $\left(\mathrm{L}^{*} \mathrm{~W} * \mathrm{D}\right)$ to make the core pad for the cushion (Figure 5).

\subsubsection{Coating of Bamboo Nonwoven Lining Material Using Thuthi}

Non-woven bamboo material was cut to the required size of the cushion along with seam allowance. 50 grams of thuthi powder was made into a smooth paste using water and was evenly applied on both side of non-woven material and dried in hot air oven at $37^{\circ} \mathrm{C}$ for 30 minutes.

\subsubsection{Preparation of Single Jersey Fabric}

The single jersey material was checked for its dimensional stability at NIFT-TEA college Textile Testing Lab as per ISO standard procedure.( Table 1). Then it was cut into the required size along with seam allowances.

\subsubsection{Preparation of Therapeutic Cushion}

Thuthi coated nonwoven material was folded lengthwise and two sides of the fabric was stitched using lock stitch machine to make a pouch.

Prepared vetiver pad was kept inside the pouch (Figure 6) and the open side was closed by lock stitching process.

This pouch will protect the vetiver pad from deformation when load is applied on it.

To prepare cushion cover Bamboo knitted fabric (single Jersey) was folded length wise and the two opposite sides are stitched using over lock machine and the open end is finished by flat lock machine using bound seam technique.

Finally the bamboo lined vetiver pad is kept inside the knitted pouch. Now the therapeutic cushion is ready for use (Figure 7).

\subsubsection{Wear Study}

The prepared therapeutic cushions were distributed to the identified truck drivers and they were instructed to use it for six weeks continuously. Feedback was collected from the drivers after the specified time and recorded. 


\section{RESULT AND DISCUSSION}

Table 1. Dimensional Stability of Single Jersey- Cushion Cover Fabric

\begin{tabular}{llll}
\hline Particulars & $\begin{array}{l}\text { Before } \\
\text { Washing } \\
\text { measurements }\end{array}$ & $\begin{array}{l}\text { After Washing } \\
\text { Measurements }\end{array}$ & $\begin{array}{l}\text { Percentage } \\
\text { of Shrinkage }\end{array}$ \\
\hline $\begin{array}{l}\text { Bamboo knitted fabric } \\
\text { (Fusia Color) - Length }\end{array}$ & $50 \mathrm{~cm}$ & $49.5 \mathrm{~cm}$ & $-1 \%$ \\
$\begin{array}{l}\text { Bamboo knitted fabric } \\
\text { (Fusia Color) - Width }\end{array}$ & $50 \mathrm{~cm}$ & $48.75 \mathrm{~cm}$ & $-2.5 \%$ \\
\hline
\end{tabular}

The single jersey fabric had a shrinkage percent of 1 percent in the wales direction and 2.5 percent in the coarse direction.

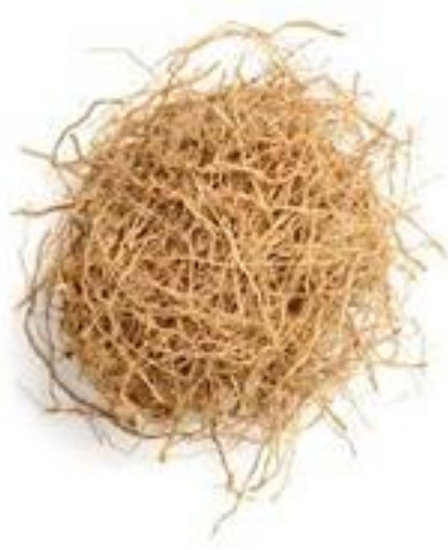

Figure 1. Chrysopogon zizanioides (Vetiver)

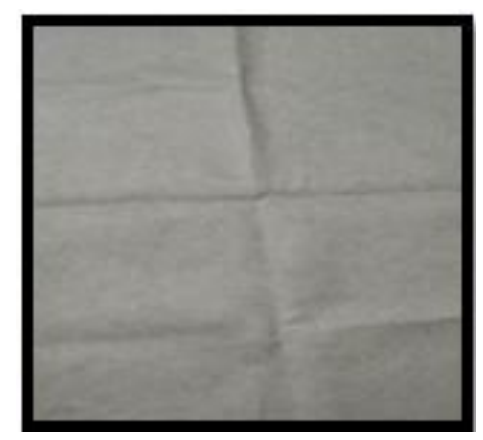

Figure 2a. Bamboo nonwoven fabric

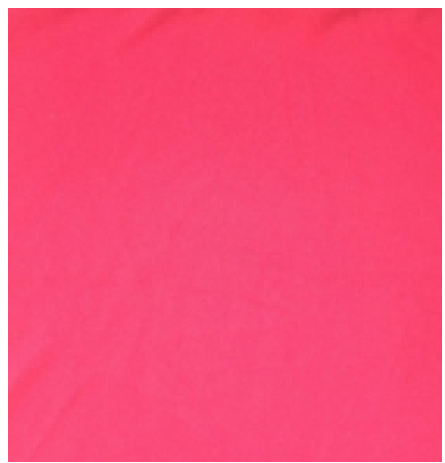

Figure 2b. Bamboo single jersey fabric

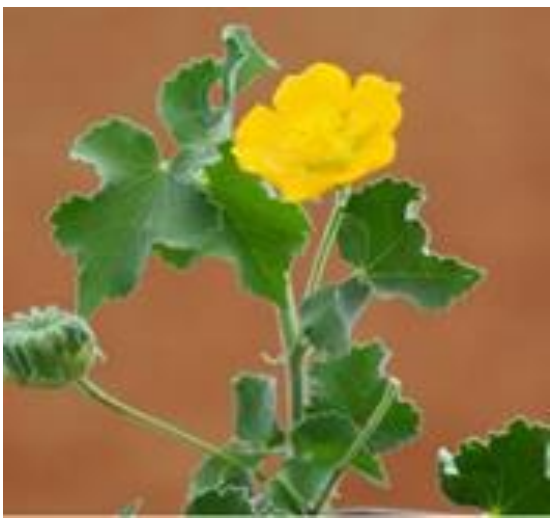

Figure 3. Thuthi (Abutilon Indicum) Plant

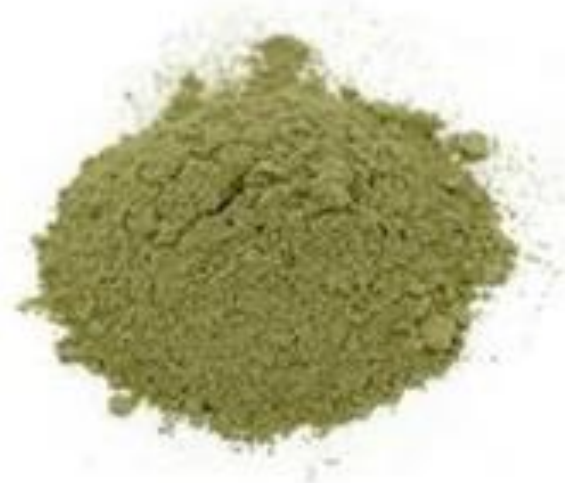

Figure 4. Thuthi (Abutilon indicum) powder

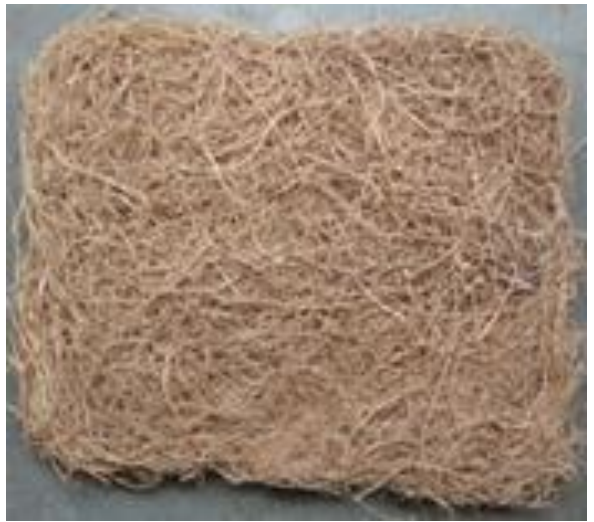

Figure 5. Vetiver (Chrysopogon zizanioides) pad 


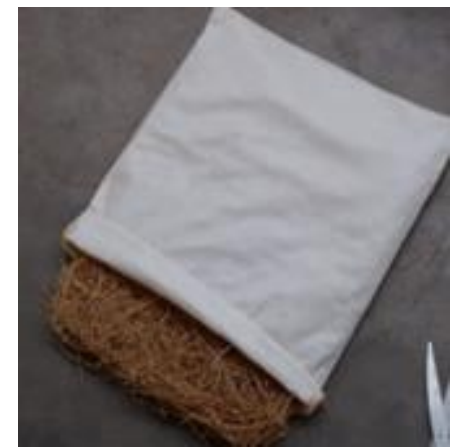

Figure 6. Vetiver (Chrysopogon zizanioides) pad 1

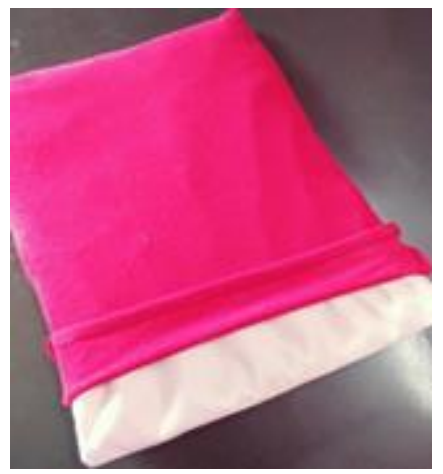

Figure 7. Vetiver (Chrysopogon zizanioides) Pad 2

Feedbacks of the drivers regarding performance of the product are presented in Figure 8.

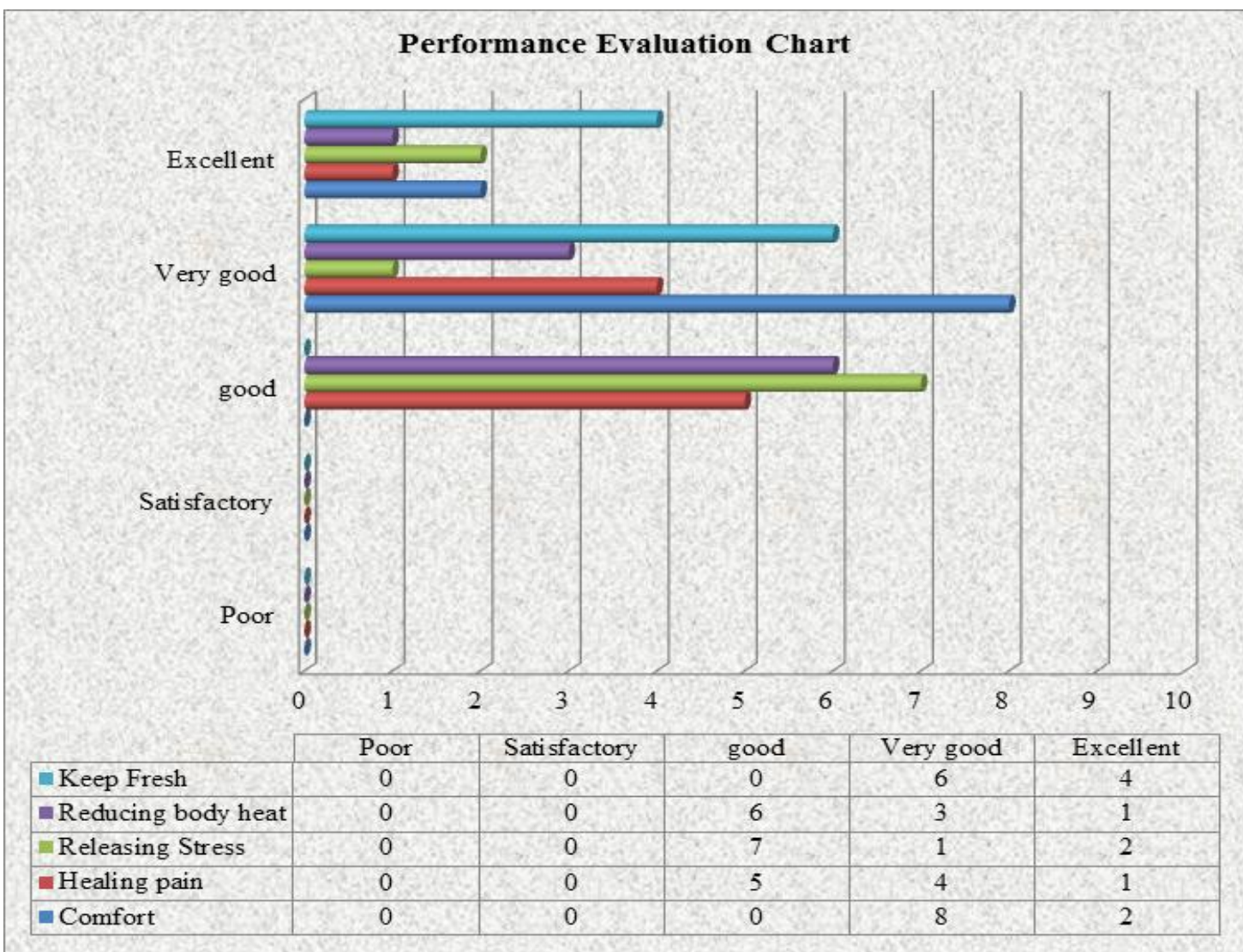

Figure 8. Performance evaluation 
When asked about the freshness of the cushion $60 \%$ of the drivers felt it was very good and $40 \%$ said it was excellent. With regard to reduction of heat $60 \%$ felt it was good, 30\% said it was very good and $10 \%$ felt it was excellent. As for as releasing of stress is concerned $70 \%$ percent said it was good, $10 \%$ felt it was very good and $20 \%$ excellent. $50 \%$ of the drivers said the cushion was good at healing pain, $40 \%$ said very well and $10 \%$ felt it was excellent. When asked about comfort $80 \%$ said it was very good and $20 \%$ felt it was excellent.

As per the report, the therapeutic cushion provided a better solution for their health issue and also reduces the adverse impact of hemorrhoids. Moreover, the aromas of vetiver kept them fresh and reduced their stress. This special cushion didn't emit much heat as the regular cushion what they have used. It may be due to the herbs and the textile materials which are used in the products. Moreover, this cushion is made from $100 \%$ biodegradable raw materials and it will be a sustainable alternative to conventional foam cushions.

\section{CONCLUSION}

Herbals have always proved their, immense potential to cure different kinds of diseases without any side effects. Compared to allopathic treatment, they have relatively low cost and can be of great benefit to the consumer. The result achieved from this study based on herbal related textiles definitely is a solution to hemorrhoids issues. Further, there is a huge scope for herbal based therapeutic textiles in future.

\section{ACKNOWLEDGEMENT}

The authors wish to express gratitude to their respective academic institutions for encouraging them to do the research study and thus enhance their career goals. The authors owe their thanks to all the participants of the research for their support and cooperation. Nevertheless, we are very grateful to the people who supported us directly or indirectly to finish the project successfully. Finally we express our sincere thanks to our family members for their moral support.

\section{REFERENCES}

[1]. Erdumlu, N., Ozipek, B. (2008). Investigation of Regenerated Bamboo Fiber and Yarn Characteristics. FIBRES \& TEXTILES East Eur. 16(4) 43-47.

[2]. Hengshu, Z. (2004). Study on the Characteristics of Bamboo Fiber in Spinning and Weaving. J Textile Res. Vol. 25, 91-93.

[3].Liu, L., Wang, Q., Cheng, L., Qian, J., Yu J. (2011) Modification of Natural Bamboo Fibers for Textile Applications. Fibers Polym. 12(1) 95-103. doi: 10.1007/s12221-011-0095-3

[4]. Yueping, W., Ge, W., Haitao, C., Genlin, T., Zheng, L., Feng, X.Q., Xiangqi, Z., Xiaojun, H., Xushan, G. (2010). Structures of Bamboo Fiber for Textiles. Text. Res. J. 80(4) 334-343. doi: $10.1177 / 0040517509337633$

[5]. Tirtha. S.S.S. (1998). Overview of Ayurveda. In the Ayurveda Encyclopedia: Natural Secrets to Healing, Prevention and Longevity (Eds. Amrit Kaur Khalsa and Rob Paon Satyaguru Publications), p 3-11.

[6]. Balasankar, D., Vanilarasu, K., Selva Preetha, P., Rajeswari, S., Umadevi, M. Debjit Bhowmik (2013). Traditional and Medicinal Uses of Vetiver. Journal of Medicinal Plants Studies. 1(3) 191-200.

[7]. Babar, A., Naser Ali Al-Wabel, Saiba, S., Aftab, A., Shah, A., Firoz, A. (2015). Essential Oils Used in Aromatherapy: A Systemic Review. Asian Pacific Journal of Tropical Biomedicine. 5(8) 601-611. doi: 10.1016/j.apjtb.2015.05.007

[8]. Rajeshwari, S., Sevarkodiyone, S.P. 2018. Medicinal Properties of Abutilon indicum, Academia Journal of Medicinal Plants. 6(4) 062-065. doi: 10.15413/ajmp.2018.0110

[9]. Wellness Ayurveda: Perfect Health and Wellness Naturally, Retrieved from https://vaishali2013.blogspot.com

[10]. Retrieve from www.nhp.gov.in

[11]. Formulated Ayurvedic Herbal Products. Retrieved from www.ayush.com

[12]. Owshadham. Retrieved from https://owshadham.blogspot.com 